\title{
Analysis of shallow bias tunnel influence factors in mountain area
}

\author{
Lin Ma \\ Shanxi Transportation Research Institute, Key Laboratory of Highway Construction \& Maintenance Technology in Loess \\ Region, Ministry of Transport,Taiyuan,030006 \\ 327759595@qq.com
}

\begin{abstract}
Shanxi loess tunnel has the characteristics which are numerous and complex geological. This paper simulated the construction process of loess tunnel by the finite difference software FLAC3D, analyzed the influence on the tunnel roof longitudinal settlement and horizontal ground surface settlement by different elastic modulus, cohesion, friction angle, Poisson's ratio, excavation step. Gave empirical formula that tunnel uneven settlement of maximum gradient and maximum surface settlement with them under the various influence factors and various factors to the sensitivity level of tunnel construction deformation which are elastic modulus $>$ cohesion $>$ friction angle. The results provide guidance for the tunnel design.

Keywords-tunnel; modulus; cohesion; friction angle; settlement
\end{abstract}

\section{INTRODUCTION}

With the continuous improvement of comprehensive national strength, China's highway network planning is continuous improvement. Especially in the western region, the highway developed rapidly. Due to the western region undulating terrain, it inevitably emerges a large number of loess tunnel. Loess large porosity, collapsible, vertical joints development and other features[1-2] make it difficult to build a tunnel in loess areas.

Currently the methods for tunnel problems research are more. There are mainly theoretical calculation method [3], the field test method [4-7], the numerical simulation method, etc. Theoretical calculation method can more accurately calculate the structure of the force and moment characteristics of the tunnel. But because of its own shortcomings it is difficult to consider more factors. Although the field test method can monitor real changes in the structure of the tunnel surrounding rock. But the resulting data are often discrete large. $\mathrm{I} t$ is difficult to find some basic laws. In view of this numerical simulations makes up for these shortcomings validly. It can not only qualitatively simulate tunnel excavation process, but also consider the impact of different factors on the tunnel deformation.

So for many of Shanxi Province typical loess tunnel, combined with the specific tunnel project, the paper simulated the main impact factors in the loess tunnel construction process using the finite difference software FLAC3D and analyzed the force and deformation of loess tunnel.

\section{PROJECT OVERVIEW}

The 2nd Longwang Temple tunnel in Kelin highway is located on the north of Hou Village $600 \mathrm{~m}$. The length of right hole is 376 meters. Starting hole mileage stake is $\mathrm{K} 113+401$. End hole mileage stake is $\mathrm{K} 113+777$. Landforms of the tunnel site is hilly region. Tunnel was east-west. Micro-topography is the ramp. Lithology is mainly Quaternary alluvial and aeolian silt and silty clay Tertiary.

\section{COMPUTATIONAL MODEL}

According to Saint-Venant principle and tunnel engineering, models only consider a range of soil traits. The tunnel located in loess formations, basically covered by loess. Therefore, in this paper the calculate soil is loess. According tunnel surrounding terrain, the model is shown in Fig .1. The numerical model is shown in Fig .2. Computational domain is taken as $60 \mathrm{~m} \times 35 \mathrm{~m} \times 44 \mathrm{~m}$. Soil strength criterion selected mohr-coulomb criteria. Model parameters are shown in table 1. 


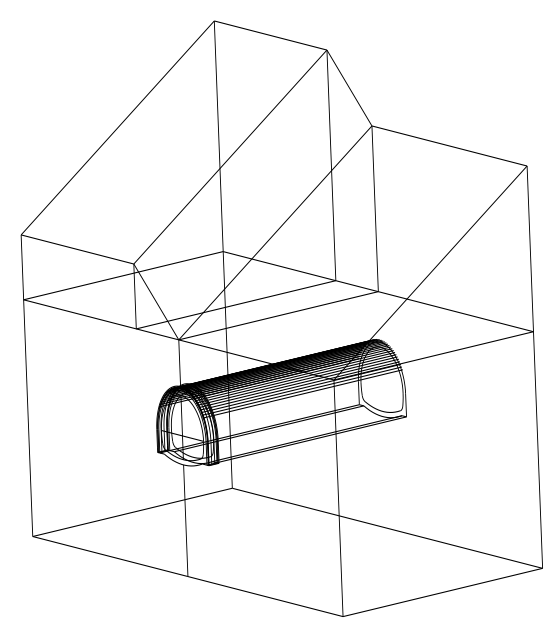

Figure 1. schematic model

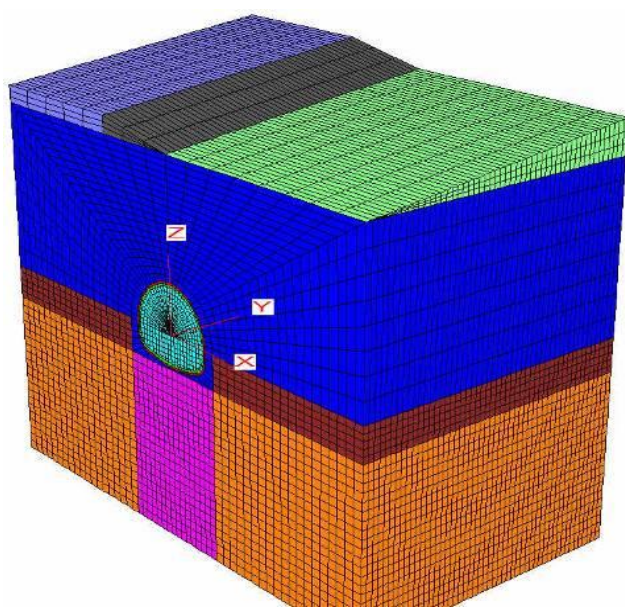

Figure 2. computational model

TABLE I . MODEL CALCULATION PARAMETERS

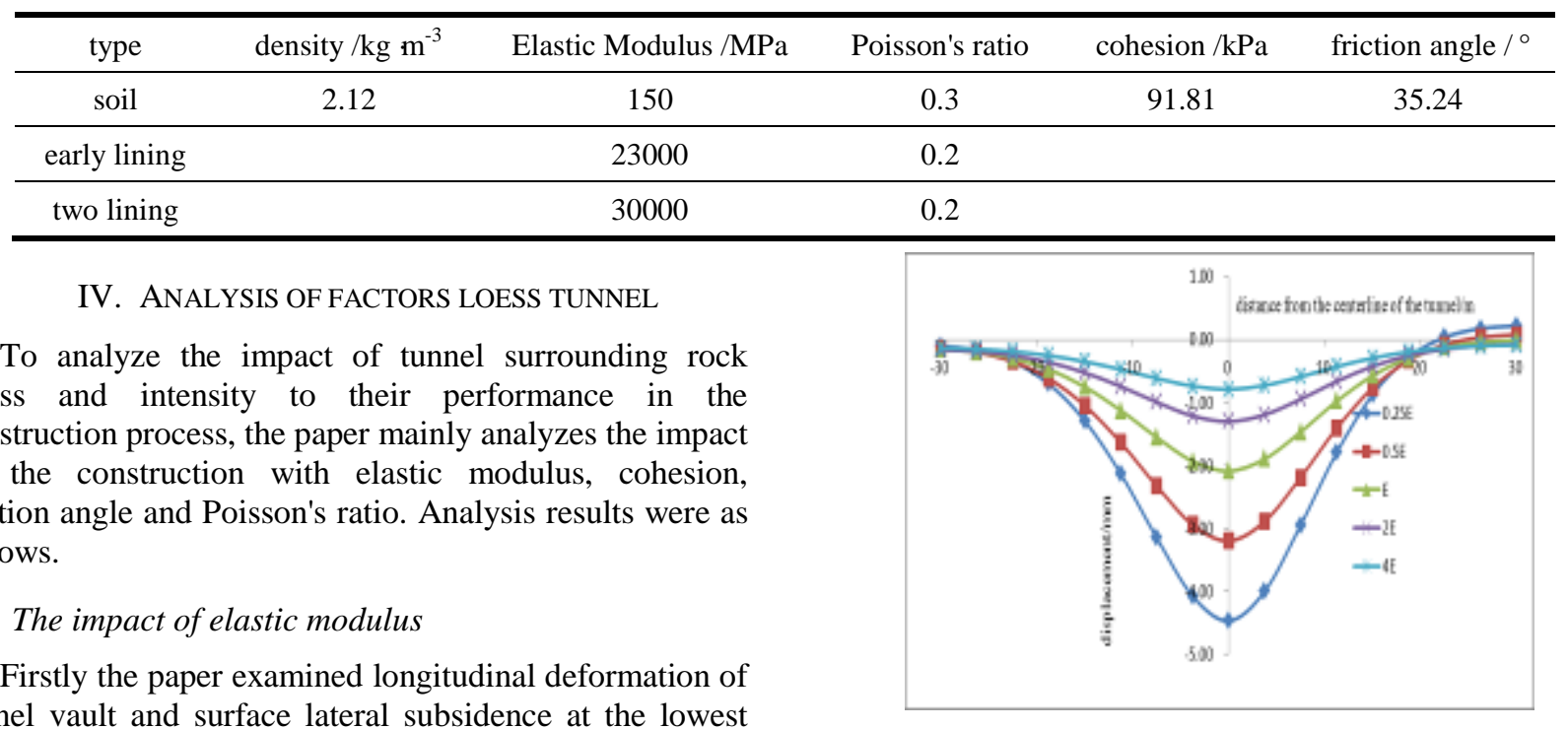

Figure 4. surface lateral subsidence curve position when the tunnel face excavation located at 21.7 meters. The results are shown in Fig .3 and Fig .4.

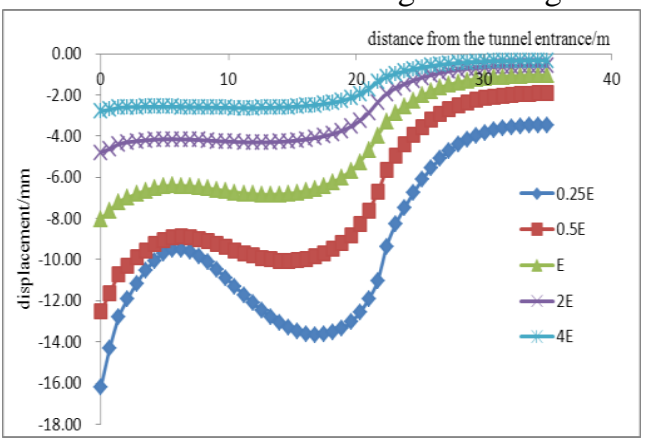

Figure 3. tunnel vault vertical settlement curve
It is difficult to see from Fig .3 that tunnel roof settlement broadly divided into three parts in the construction process. Vault overall settlement which is from face front about $2 \mathrm{~m}$ to more distant is small and slow to change. Vault overall settlement which is from face behind about $1 \mathrm{~m}$ to more distant is larger and change is slow. The dome settlement dramatic changes at face front 2 meters to 1 meter behind. The gradient is largest. This place is also the most dangerous section of the disease occurrence. Fig .4 reveals surface subsidence shows settling tank shape in the process of tunnel excavation and it is consistent with the Peck theory. The left side surface sinks and the right surface slightly uplift. With the increase of the elastic modulus, the roof and surface subsidence significantly reduced. 


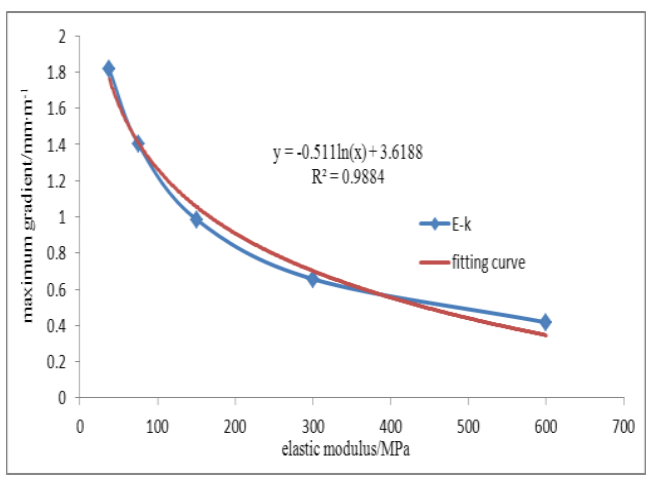

Figure 5. the curve of the tunnel maximum gradient with elastic

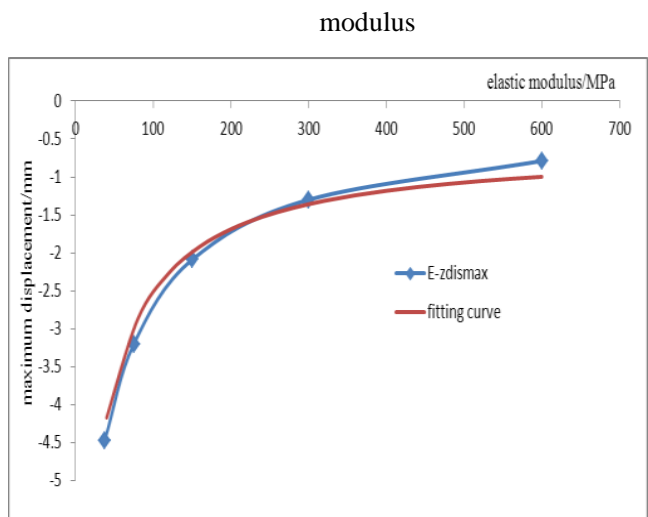

Figure 6.

the curve of the surface maximum displacement with elastic modulus

Fig .5 and Fig .6 shows the tunnel roof maximum gradient and maximum surface subsidence associated with the elastic modulus showed good law. By regression analysis, it can predict the tunnel maximum gradient and surface maximum settlement under different elastic modulus. Fitting formula is shown formula 1 and 2 .

$$
\begin{aligned}
k_{\max } & =-0.51 \ln E+3.6188 \\
s_{\max } & =-\frac{1}{a+b * E}+c
\end{aligned}
$$

In formula $\mathrm{a}$ is $0.12, \mathrm{~b}$ is 0.004 and $\mathrm{c}$ is -0.6 .

\section{B. The impact of cohesion}

Fig .7 and Fig .8 shows the changes of cohesion with roof vertical settlement and surface lateral settlement when the tunnel excavated.

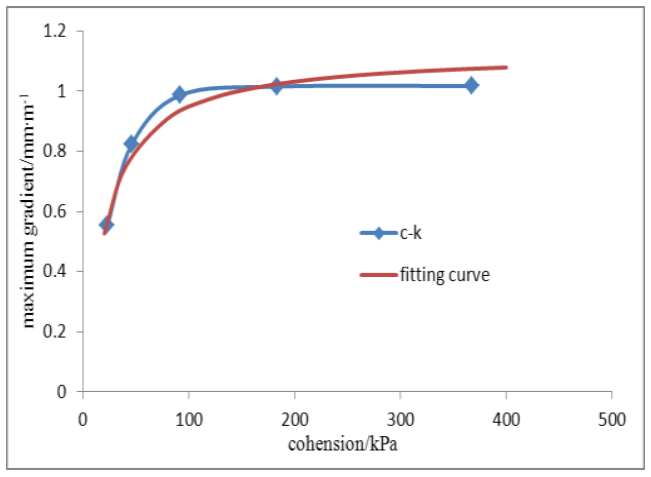

Figure 9. the curve of the tunnel maximum gradient with cohesion

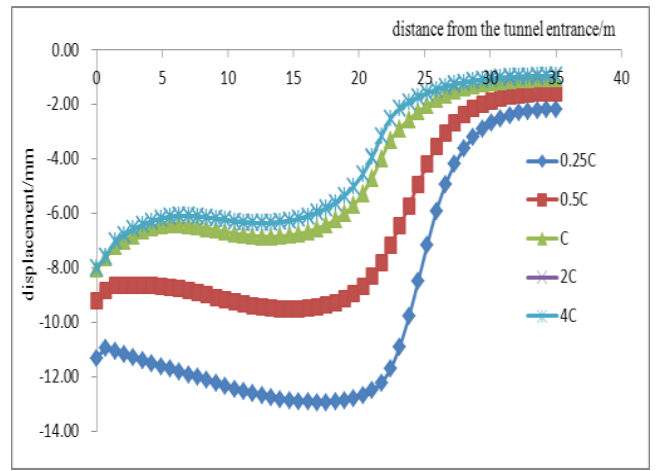

Figure 7. tunnel vault vertical settlement curve

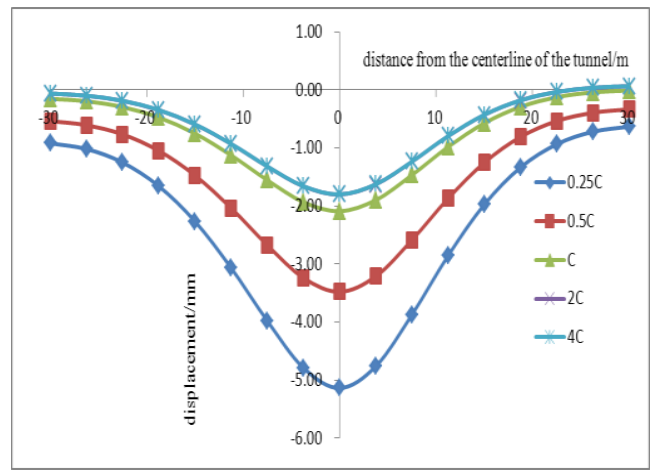

Figure 8. surface lateral subsidence curve

Fig .7 and Fig .8 show a similar curve shape and Fig .3 and Fig .4. The difference is that with the increase of cohesion, the roof and surface subsidence are gradually reduced. But when the cohesion increases to $4 \mathrm{C}$, the settlement no longer increases, indicating that the soil deformation changes with cohesion is a limit. The reason is that cohesion describes cementation among loess particles. cohesion is greater and cementing material is more, then cementation is also stronger, namely soil strength is higher. But loess is with large pore structure, the cement material can only be filled with adjacent particles. With the growing number of cement material, the gap between adjacent particles continue to decrease, eventually to zero.

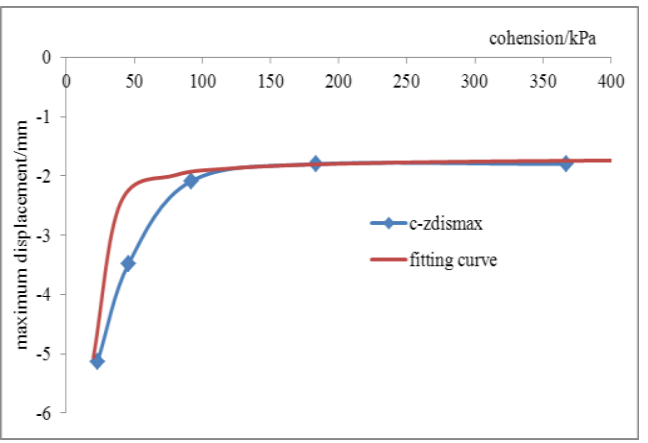

Figure 10. the curve of the surface maximum displacement with cohesion 
Fig .9 and Fig .10 shows the variation of the maximum

$$
\begin{aligned}
& k_{\text {max }}=\frac{c}{a+b * c}+m \\
& s_{\text {max }}=\frac{c}{a+b * c}+m
\end{aligned}
$$

TABLE II . FITTING FORMULA PARAMETER TABLE

\begin{tabular}{ccccc}
\hline formula & parameter $a$ & parameter $b$ & $m, n$ & remark \\
\cline { 1 - 4 } 3 & 10.2 & 0.7 & -0.3 & $c$ is \\
\cline { 1 - 4 } 4 & 10.2 & 0.72 & -0.3 & cohesion \\
\hline
\end{tabular}

\section{The impact of friction angle}

Inspect the variation of tunnel roof subsidence and surface subsidence with friction angle in the tunnel excavation process. They are just as follows.

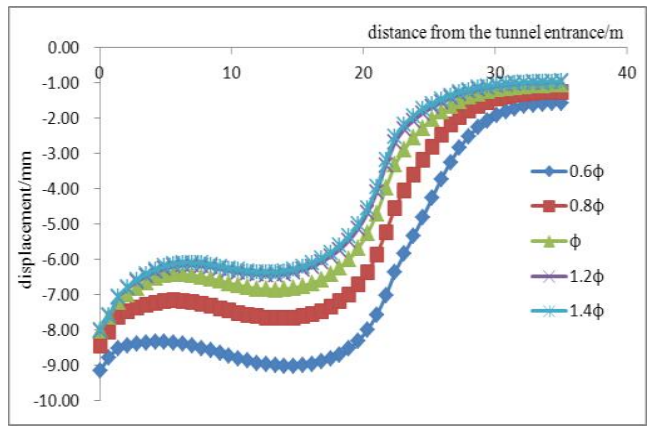

Figure 11. tunnel vault vertical settlement curve

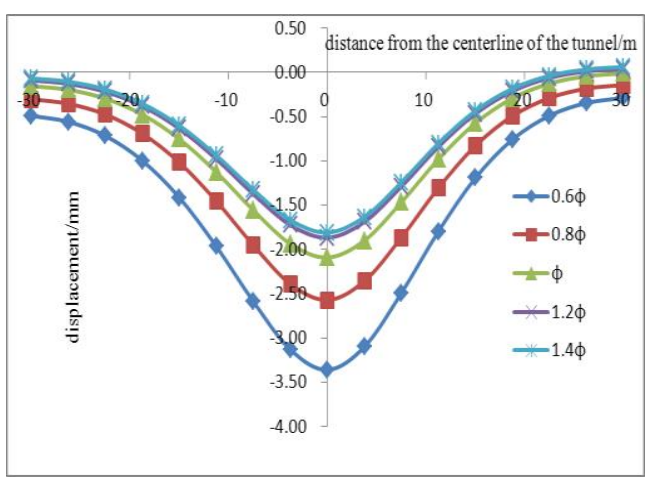

Figure 12. surface lateral subsidence curve

Fig .11 and Fig .12 shows a tunnel roof longitudinal subsidence and surface lateral subsidence decreases with friction angle increases, eventually stabilizes. The reason is that the friction angle refers to the friction between the particles. It is related to the engagement degree and the surface roughness of the particles. When the friction angle increasing, it indicates that the surface roughness of the soil particles increases, the bite force is also enhanced.

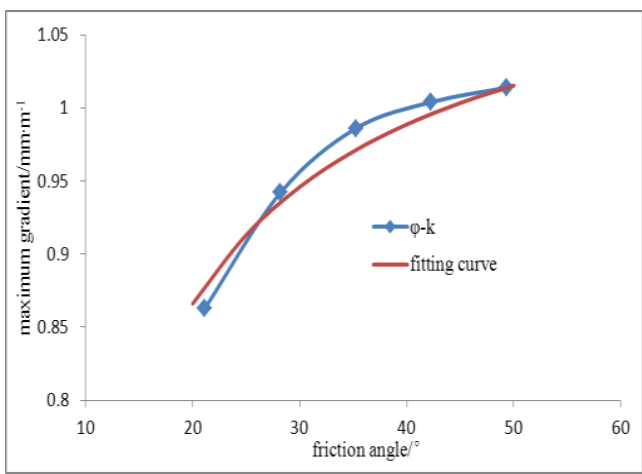

Figure 13. the curve of the tunnel maximum gradient with cohesion

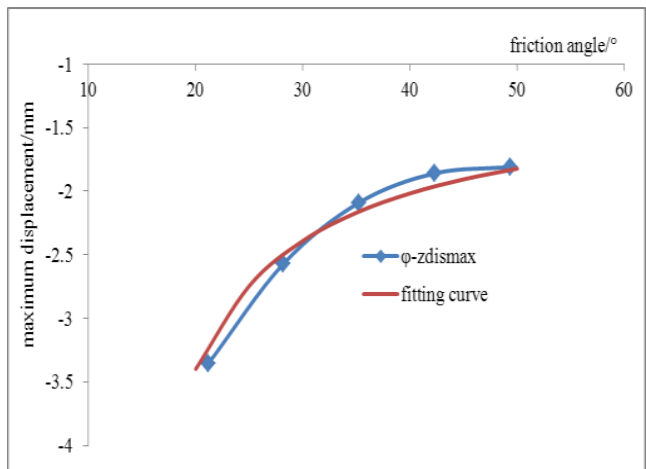

Figure 14. the curve of the surface maximum displacement with cohesion

Fig .13 and Fig .14 show the relationship between the tunnel roof subsidence and surface maximum subsidence with friction angle is hyperbolic. Their fitting expression is as follows.

$$
\begin{aligned}
& k_{\text {max }}=\frac{\varphi}{a+b * \varphi}+c \\
& s_{\text {max }}=\frac{\varphi}{a+b * \varphi}+c
\end{aligned}
$$


TABLE III. FITTING FORMULA PARAMETER TABLE

\begin{tabular}{cccc}
\hline formula & parameter $a$ & parameter $b$ & parameter $c$ \\
\hline 5 & 1.52 & 0.5 & -0.87 \\
\hline 6 & 2.64 & -0.32 & 1.92
\end{tabular}

\section{IN CONCLUSION}

(1) Gave empirical formula that tunnel uneven settlement of maximum gradient and maximum surface settlement with them under the various influence factors.

(2) Obtained various factors to the sensitivity level of tunnel construction deformation which are elastic modulus $>$ cohesion $>$ friction angle.

\section{REFERENCES}

[1] Liu Zudian. Loess Mechanics and Engineering [M]. Shaanxi Science and Technology Press, 1997.

[2] Gao Guorui. Loess microstructure classification and collapsibility[J]. China Science ,1980, Vol.(12), pp: 1203-1208.

[3] Peck R.B, Deep excavation and tunneling in soft ground, State of the Art Report. Proc. 7lnt.Conf. On Soil Mechanics and Foundation Engineering, Mexico City, 1969,pp: 225-290.

[4] Wang Keyong. The Study on Deformation Characteristics of Tunnels in Collapsible Loess[J]. Soil Engineering and Foundation, 2013, Vol.27(2), pp: 71-74.

[5] Yu Ning, Zhu Hehua. Application on safety monitoring forecasts in highway tunnel construction[J]. Modern Tunneling Technology, 2003, Vol.40(5),pp:59-66.
[6] Tan Zhongsheng, Yu Yu, Wang Mingnian. Experimental research on bolt anchorage effect on large-section deep buried tunnel in loess $[\mathrm{J}]$. Chinese Journal of Rock Mechanics and Engineering, 2008, Vol.27(8),pp:1618-1625.

[7] Chen Jianxun, Jiang Jiuchun, Wang Mengshu. Function of rock bolt of lattice girder and shotcrete support structure in loess tunnel[J]. China Journal of Highway and Transport, 2007 Vol.20(3),pp:71-75

[8] Gong Yuxia, Sun Zhijie. Analysis on spatial effect of tunnel Lining deformation characteristics and structure size optimization[J]. Shanxi science and technology communications, 2012, Vol. (3),pp: 41-44.

[9] Hu Shimin, Zhang Dingli, Wang Mengshu. The mechanical respone of the surrounding rock caused by the excavation of loess tunnel with large cross section[J]. China railway science, 2011, Vol.32(5), pp:50-55.

[10] Li Yuling, Li Wenyuan. Explicit analysis of ground reaction curve tunnel excavation[J]

Chinese Journal of Rock Mechanics and Engineering, 2010 Vol.29(S2),pp: 3685-3692.

[11] Liu Jiguo, Zeng Yawu. Application of FLAC3D to simulation of foundation excavation and support[J]. Rock and soil mechanics, 2006, Vol.27(3),pp: 505-508.

[12] Wang Cangang, Zhang Yun. Application of FLAC3D to analyze stability of shallow tunnel[J]. Geotechnical engineering world, 2007, Vol.11(2),pp: 50-55. 